Book Power in Communication, Sociology and Technology

Ed. Angela Repanovici, Manolis Koukourakis, Tereza Khecyoyan

Series: Philosophy, Communication, Media Sciences

Available online at http://trivent-publishing.eu/

\title{
The Interpretation of Knowledge Economy and the Problems of Its Rise and Development in Armenia
}

\author{
Tereza Khechoyan \\ Public Administration Academy of the Republic of Armenia, \\ Armenia, aspa.paara@gmail.com
}

\begin{abstract}
This paper analyses the socio-economic factors of knowledge economy in Armenia. The presented problem of exploration focuses on the determinants and conditions for a new type of economy development and the correlation between the factors and incentives of rising and developing knowledge economy. The research is based on exploring and revealing the main causes and prerequisites which generated favourable conditions for knowledge economy, as well as on analysing methods to accelerate its development in the country. The study and discussion of the knowledge economy in Armenia is done first of all in terms of IT. The educational, taxing, management systems and effective cooperation between public and private sectors are considered to be important factors in the development of knowledge economy.
\end{abstract}

Keywords: Knowledge economy; information society; innovation; national competitiveness; IT sector; science-based economy.

This is an Open Access article distributed in accordance with the Creative Commons Attribution Non Commercial (CC-BY-NC-ND 4.0) license, which permits others to copy or share the article, provided original work is properly cited and that this is not done for commercial purposes. Users may not remix, transform, or build upon the material and may not distribute the modified material (http:/ / creativecommons.org/ licenses/by-nc/4.0/) 


\title{
The Interpretation of Knowledge Economy and the Problems of Its Rise and Development in Armenia
}

\author{
Tereza Khechoyan \\ Public Administration Academy of the Republic of Armenia, \\ Armenia
}

\section{Understanding the term, concept, and phenomenon of knowledge economy}

\section{Historical overview}

The term "Knowledge Economy" was introduced by Fritz Machlup. In 1962, the economist published an influential study ${ }^{1}$ that measured the production and distribution of knowledge in the United States. Machlup's calculations gave rise to an entire literature on knowledge economy, its policies and measurement. However, knowledge economy as a phenomenon raised before the researchers' scientific approach to it.

For discussing and analysing the phenomenon of knowledge economy, we should approach the social and economic evolution of society.

Industrialisation made huge changes in global economy and gave a start to the formation of the industrial society. Many scientific sources use the term industrial revolution to underline the importance of its changes and transformations in global economy. In the sense of economic efficiency, industrialisation made two important changes: the automation of production and the diversification of economy (a structure which in fact complicated it). These changes generated following important transformations for organizations:

1. Automation of production by putting production on technological base.

2. Transformation of the need for manual labour into a more qualified one

3. The complication of management functions and the emergence of strategic management in all stages of top-management (marketing, logistics, production, sales, finance, etc.)

In terms of knowledge economy, we can see the initial signs for raising knowledge based economic system. Thus, the first point concerns the technological and innovative aspects of the production, which requires generating and creating knowledge, to be more precise the know-how. The second and third points refer to using or applying knowledge. In these terms one can see that knowledge economy phenomenon revealed from industrialization. In other words, the academic concept, here as used by sociologists, reflects a shift in an industrial economy from manual to technical and scientific skills, a change which has

\footnotetext{
1 Fritz Machlup, The Production and Distribution of Knowledge in the United States (Princeton: Princeton University Press, 1962).
} 
serious implications for the kind of qualifications required by students entering the job market. $^{2}$

Though the term and concept of knowledge economy or knowledge based economy was popularized and meets in academic materials during the next stage of evolution called information society, the revealing of the phenomenon owe to industrialization and industrial economy and society. It reflects to the case when the concept and its phenomenon appears and starts its formation before the academic researchers start to study it.

The other important aspect of the knowledge economy term historical overview refers to its technological basis. Are sense and perception of knowledge economy determined and delimited to only technological frameworks and scopes? Definitely no. As one can see from the above listed points, though the first two points requires technological skills, the third one concerning to the administrative and strategic management of the organization may not demand technological skills and the technology itself. Though the technological knowledge plays grand and principal role in modern economy, the knowledge based economy requires and supposes generating, transferring, processing and using knowledge in general.

\section{Modern interpretation: Trends and Implications}

The modern interpretation of knowledge economy is influenced in many ways by nowadays' social and economic tendencies: globalization, information society and technological and scientific progress.

Knowledge economy is evidence in all developed countries and a challenge for developing countries with few natural resources. The economic growth is considered in the context of knowledge economy. Economic growth increasingly depends on the ability to acquire new knowledge and apply it in all areas of life. ${ }^{3}$

As it was mentioned before, the term "knowledge economy" was introduced by Fritz Machlup. ${ }^{4}$ Anyway the term was popularized and put in to use by Peter Drucker. ${ }^{5}$ Machlup defines the term as "One of the economy sectors, in which knowledge is produced, processed and managed." Drucker uses another definition: "A type of economic system, where knowledge plays essential role and knowledge production leads to economic development." As we can see, Drucker in his definition links the knowledge economy to economic growth. In this context we should distinguish the two different concepts: knowledge economy and knowledge based economy. The first one is a sector of economy, a market where the main product - knowledge is generated, used and transferred. The second one is an economic system.

There are two organizations, which are strongly integrated into researching and studying knowledge based economies: OECD and World Bank. OECD in its report defines the knowledge based economies as "economies which are directly based on the production, distribution and use of knowledge and information"." The OECD uses the term "knowledge economy" to draw attention to the importance of knowledge in all economic activities. The definition has been evolving from focusing just on manufacturing industries

\footnotetext{
2 Robert Cowen, Andreas M. Kazamias, International Handbook of Comparative Education (Springer International Handbooks of Education, 2009), 519-520.

3 Olena Vinnychuk, Larysa Skrashchuk, Igor Vinnychuk, "Research of Economic Growth in the Context of Knowledge Economy”, Intellectual Economics (2014), 116-127.

4 Fritz Machlup, The Production and Distribution of Knowledge in the United States (Princeton: Princeton University Press, 1962).

${ }^{5}$ Drucker PF, Post-Capitalist Society (New York: Harper Bus, 1993).

6 OECD Report "Knowledge Based Economy," 1996, p. 7.
} 
that make intensive use of technology to including services that are also heavily knowledge based.

The World Bank uses the following definition: "A knowledge economy is one where organizations and people acquire, create, disseminate and use knowledge more effectively for greater economic and social development." World Bank developed the knowledge economy measuring indicators, which are already in common use worldwide. Introduced by World Bank there are 2 indicators for measuring knowledge economy:

1. Knowledge Index

2. Knowledge Economy Index (ranked).

The countries are divided into 4 groups from 0 (worst) to 10 (best) points. The knowledge economy index is calculated by 109 structural and qualitative indicators, which are grouped in 4 types.

1. Economic Incentive and Institutional Regime

2. Education and Human Resources

3. Innovation System

4. Information and Communication Technology.

As we have seen, modern interpretation of knowledge economy gives great importance to its connection to economic growth and of course to its influence on it. Another tendency in researching of knowledge economy concept is linked to terms like science economy and "scientification" of economy. Science linkage with industry is found not only in sciencebased industries, such as pharmaceuticals and electronics, but also in many other industries. ${ }^{8}$ Academic sector is getting more involved in patenting activities, and that scientific knowledge generated in the sector is being utilized not only in science-based industries, but also in many others. The transformation from science (paper) of academic field to technology (patents) of industry field happens faster and smoother.

With all productive researches in the field of knowledge economy, there are still problems with measuring the knowledge itself and its impact on economic growth. Studying the theme of knowledge economy we have encountered some difficulties and incomprehensibilities in the terms of interpretation of the phenomenon and term of knowledge economy. We considered important and useful for further researchers to identify, distinguish, define and divide the main problems into 4 groups:

1. There are no all-purpose indexes or other indicators that can be adopted to calculate all types of economies. In fact, every economy is a separate case because of its unique structures, strengths, weaknesses and challenges. We consider that the World Bank's indexes cannot be used as universal for all types of economies, because very often they are not indicative for the situation in the economy.

2. Often there is no correlation between knowledge economy index components and IT sector development in some countries (including case of Armenia).

3. The term of knowledge economy is still on it's stage of formation. The meaning and implication of the term are still "floating". Very often researchers imply different concepts by the term of knowledge economy.

4. The impact of knowledge economy development on economic growth of whole economy is obvious. Nevertheless, the mechanism by which the knowledge economy influences the economic growth is still under examination.

\footnotetext{
7 World Bank Institute Report, "The Knowledge Economy, The Kam Methodology And World Bank Operations," 2006, p. 4.

8 Kenta Ikeuchi, Kazuyuki Motohashi, Ryuichi Tamura, Naotoshi Tsukada, CEPR's policy portal 2017 https://voxeu.org/article/new-indicators-science-intensity-industry (accessed December 15, 2017).
} 
In this work, for the case of Armenia we will use the term knowledge economy implying the economic sector and the term knowledge based economy implying the economic system. But in some cases the use of the term of knowledge economy will imply the economic system of knowledge itself. We want to underline the link between knowledge economy and knowledge based economy. The main aim of knowledge economy development is to form a knowledge based economy. In other words, the final point of the development of economic sector of knowledge is the formation of knowledge based economic system.

\section{Knowledge economy problems in Armenia}

\section{Current Situation and Indexes}

During the Soviet Union years, Armenia was in the first places with indicator of number of scientists per capita among soviet republics. The exact sciences were the most developed during those years (Physics and Engineering). After the independence a big number of scientists have been migrated due to difficult social and political situation and absence of infrastructures. We must note that during the soviet years the Armenian economy of science and knowledge was a part of a big soviet system. After the independence, as a result the economic ties were severed between the small parts, and the links between science and economy became dysfunctional.

The discussion on knowledge economy formation and development started in most recent years, and it is inked to the development of IT sector of Armenia. The IT sector of Armenia during last 7 years is developing very rapidly, in average $20 \%$ per year. In fact, IT sphere is the main driving force in rising and developing of knowledge economy in Armenia.

As it was mentioned above World Bank measure the knowledge economy by indexes. In this paper we are focused only in World Bank data. The most important indexes for Armenia are represented in the Table 1 ?

Table 1. Indexes concerning knowledge economy in Armenia

\begin{tabular}{|c|c|c|c|c|c|}
\hline Indicator & Measure & Units & 1995 & 2000 & 2012 \\
\hline \multirow{2}{*}{$\begin{array}{c}\text { Knowledge } \\
\text { economy } \\
\text { index }\end{array}$} & Unweighted & Index $(0=$ lowest; $10=$ highest $)$ & 5.01 & 5.27 & 4.88 \\
\hline & $\begin{array}{l}\text { Weighted by } \\
\text { population }\end{array}$ & Index $(0=$ lowest; $10=$ highest $)$ & 5.25 & 5.57 & 5.08 \\
\hline \multirow[b]{2}{*}{$\begin{array}{c}\text { Knowledge } \\
\text { Index }\end{array}$} & Unweighted & Index $(0=$ lowest; $10=$ highest $)$ & 5.74 & 5.35 & 4.57 \\
\hline & $\begin{array}{l}\text { Weighted by } \\
\text { population }\end{array}$ & Index $(0=$ lowest; $10=$ highest $)$ & 6.07 & 5.75 & 4.84 \\
\hline \multirow{2}{*}{$\begin{array}{l}\text { Knowledge } \\
\text { economy } \\
\text { rank }\end{array}$} & Unweighted & Rank ( $1=$ the best $)$ & 76 & 62 & 75 \\
\hline & $\begin{array}{l}\text { Weighted by } \\
\text { population }\end{array}$ & $\operatorname{Rank}(1=$ the best $)$ & 67 & 58 & 71 \\
\hline
\end{tabular}

The World Bank's indexes are very often not indicative and illustrative for separate cases, and the case of Armenian is among them. The presented indexes cannot explain the phenomenon of fast development of IT sphere in Armenia, which is always one of the driving forces of knowledge economy. According to the presented index values, Armenia is far from having developed knowledge economy, and its rank illustrates it (75). Nevertheless, Armenian IT sector is showing a big growth year by year. This contradiction may be

\footnotetext{
${ }^{9}$ The World Bank’s Knowledge Assessment Methodology (KAM: www.worldbank.org/kam).
} 
explained by the structure of knowledge economy index, which as we mentioned above, contains 4 types of indicators' groups. Only one of the four represents the information technologies' indicators. The other three concern the educational, institutional and innovation systems, which are in fact at an early stage of reforms in Armenia. We consider that the development of IT sector in a country generally may proceed from development of educational, institutional and innovation systems or at least the development of all four must happen similarly and accordingly, but the Armenian case shows that this chronology and logics can be broken. The Armenian IT sector shows growth despite the bad situation in other three aspects: educational, institutional and innovation systems. So, that's why the knowledge economy indexes are not indicative for the Armenian case. It's obvious that the formation and raise of knowledge economy in Armenia has started from the development of IT sphere, and that's why we suggest to study and discuss of knowledge economy in Armenia first of all in the terms of IT sector.

\section{IT sector of Armenia}

The IT and high-technology sector is one of the fastest growing sectors in the Armenian economy. In 2017 there are more than 600 IT companies in Armenia. The IT sector during the last 5 years shows growth in average $20 \%$ per year ${ }^{10}$. In 2016, the IT sector made $4.7 \%$ of the GDP of Armenia. According to non official statistics the total number of skilled personnel working in IT sphere has reached $15000^{11}$. Besides, Armenia is passing through "startup boom": in 2016, there were 100 new IT companies registered in Armenia. About $13 \%$ of the companies operate in the high-technology domain, while the rest are IT companies.

One of the driving factors of sector growth was its attractiveness for foreign companies to establish branches in Armenia. The prime competitiveness factor was the availability of relatively cheap and competitive human resources in Armenia.

There are some important stakeholders in development of IT sphere in Armenia:

1. Enterprise Incubator Foundation (EIF) is one of the largest technology business incubators and IT development agencies in the region, operating in Yerevan, Armenia. Established in 2002 within the framework of the World Bank's "Enterprise Incubator" project, it is called to support the development of information and communication technology sector in Armenia through creating a productive environment for innovation, technological advancement and company growth.

2. Union of Information Technology Enterprises (UITE) is a key figure in developing IT sphere and knowledge based economy in Armenia. The Union represents the voice of all IT companies in Armenia and uses all resources to conduct the technologic sector development in Armenia managing different projects and events. UITE plays also crucial role in developing the educational system for IT sphere. UITE developed and implemented the program called "Technical Laboratories in every school". The chain of laboratories calls „Armath".

3. The Foundation for Armenian Science and Technology (FAST) launched in 2016 aims at building an ecosystem that drives technological innovation and scientific

\footnotetext{
${ }^{10}$ The Global Information and Communications Technologies (ICT) Unit. The World Bank "IT Skills Assessment in Armenia," 2014, p. 4.

11 The important factors of the 2018 for IT sector of Armenia; December 2017

https://ittrend.am/2017/12/30/armenian-it-2017/.
} 
advancement in Armenia and beyond. FAST intends to mobilize the scientific, technological, and financial resources of the Armenian and international communities. FAST was established under IDeA (Initiative for Development of Armenia) foundation.

4. Tumo Center for Creative Technologies is a free of charge digital media learning center in Yerevan, Armenia. Since its opening in 2011, the center has provided thousands of students aged 12-18 an open environment where they can use the latest in digital tools, learn from media professionals, and explore the intersection of technology and art.

There are some important annual events which promote the development of information technologies and engineering in Armenia. Here are some of them:

1. The largest regional DigiTec Expo organized every year. The Expo of 2017 hosted about 150 companies and 70000 visitors. EXPO is founded and organised by Union of Information Technology Enterprises.

2. Sevan Startup Summit is a yearly non-formal startup event. Sevan Startup Summit is a new format of a business platform where the participants have an opportunity to improve and acquire new knowledge, obtain new valuable contacts, discover new possibilities of cooperation and partnership, compete with their teams and ideas and win grants and get investment.

3. BarCamp Yerevan is a "non-conference" in the sphere of information technology or "IT, new media and Internet. A "non-conference" is the unofficial, informal part of the conference supporting open discussions and a free exchange of ideas and opinions. The main target audience of the BarCamp is engineers/developers/programmers of all flavors, project managers, entrepreneurs, new media activists, designers, educators and all professionals who are building the next generation Web.

Despite the weak cooperation between Government of Armenia and IT sector and also usually belated responses to IT sphere needs and problems, there have been done some governmental steps towards developing knowledge economy:

1. Strategy on Development of Science for 2011-2020 (May 2010). The principal targets of the Strategy are the following:

- Creation of a system capable of sustaining the development of science and technology;

- Development of scientific potential, modernization of scientific infrastructure;

- Promotion of basic and applied research;

- Creation of a synergistic system of education, science and innovation; and

- Becoming a prime location for scientific specialization in the European Research Area.

2. Science and Technology Development Priorities for 2010-2014 (May, 2010)

3. Action Plan on the Development of Science for 2011-2015 (June 2011)

4. IT Sphere Development Annual Program

5. Tax Exemption for IT companies referring to "bypassing" value-added tax (VAT)

6. The Law on promoting the IT Sphere in the Republic of Armenia (December 2017).

\section{The problems of IT sphere in Armenia}

Despite the fast development of IT sector in Armenia, some problems block its advancement and expansion. The first problem refers to educational system in Armenia. 
The problem has two sides. The first side concerns the lack of graduates in IT field. According to World Bank annually IT sphere demands 2000 new specialist, but universities can "give" only 450. The second side of the problem refers to the quality of higher education. The higher education system in Armenia lacks competitive dynamism and efficiency when it comes to IT skills. The quest to join the European Higher Education Area compels Armenia to reform. Armenia is undertaking reforms through the Bologna process in order to join the European Higher Education Area. Currently, private sector does not place high value on university degree in their recruitment practices, indicating the diminishing role and image of higher education in the sector. ${ }^{12}$ Teaching programs are not meeting the market needs. The knowledge given in the universities are too much theoretical and does not include the applied part. There is not enough scientific and practical approach in higher education system. A big number among IT sphere employees are self-taught specialists.

The second problem concerns the outsourcing model of IT companies in Armenia. The majority of IT companies starts their activities by outsourcing model for international companies due to qualified and cheap labor market. Though it is a good point to start, but it slows down the development of the company. This point is becoming a problem, because demand for IT specialists is increasing at a very high rate and Armenia starts to lose its competitive advantage. Nevertheless, during the recent years we can see a shift from outsourcing model to the model of development its own product. In this case another obstacle appears. The outsourcing model is a good start for the company because of financial stability, but if an IT company starts its activity by own product model, the problem of financing and investments stands. The investment institutions are still on the stage of formation in Armenia.

Another issue is the peculiarity of Armenian IT sector. The majority of Armenian IT companies are only software developers and engineers. Software Engineering is the study and application of engineering to the design, development, and maintenance of software. System engineering is an interdisciplinary field of engineering that focuses on how to design and manage complex engineering projects over their life cycles. As one can see system engineering is much more complex and "ambitious" field. The lack of system engineers and system engineering knowledge in Armenia limits the possible range of products development. Here the absence of necessary infrastructure also plays role.

Reciting the IT sphere problems we must also mention the lack of entrepreneurial knowledge among IT sector businesspersons. Nowadays market is structured in a way, where a good product is not enough to conquer the market and clients. Marketing, branding, management and sales knowledge plays grand role in representing IT products in international markets. IT sector specialist and managers need a higher level of entrepreneurial knowledge and skills to monetize and merchandise their products.

The absence of financial and technical infrastructure (venture funds, angel investors, crowdfunding models) is a big challenge for Armenian IT companies. Banks as a rule do not give loans to startups because of higher risks and absence of methodology to evaluate the proposed business models and plans. Venture funds do not play significant role in financing it startups. Angel investors are a rare phenomenon in Armenia. Though the Government tries to develop mechanism for financing IT startups in their seed round, the financing problems in round A and B are a big challenge. There is a developing a tendency, when a big and financially "rich" IT company invests in new startups in Armenia. The cooperation between Government and IT sector is very weak. The responses of public authorities to the

12 The Global Information and Communications Technologies (ICT) Unit. The World Bank "IT Skills Assessment in Armenia," 2014, p. 6. 
needs and problems of IT sphere are usually belated, insufficient and not effective. The cooperation between academic field and IT sector is also at a low rate. There is an acute need of research and development organizations in Armenia. During recent years, a discussion on developing and founding IT clusters in cooperation with Government, academic organizations and IT private sector has started.

Concluding, we must say that the raise and development of knowledge economy in Armenia is strongly connected to IT sphere. We must study and discuss the knowledge economy in Armenia first of all in terms of IT sphere. The phenomenon of fast development of IT sphere in Armenia with all challenges and problems is really a big achievement and the start of forming the knowledge based economy in Armenia has been given due to IT sphere. The future development of knowledge economy should be based on the achievements of IT sphere. Of course, it will demand the cooperation between all stakeholders and interested parties.

\section{References}

Cowen, Robert and Andreas Kazamias. International Handbook of Comparative Education. 519520. Springer International Handbooks of Education, 2009.

Vinnychuk O. and L. Skrashchuk, I. Vinnychuk. "Research of Economic Growth in the Context of Knowledge Economy." Intellectual Economics (2014).

OECD Report "Knowledge Based Economy" (1996).

World Bank Institute Report "The Knowledge Economy, The Kam Methodology and World Bank Operations" (2006).

Ikeuchi Kenta, Motohashi Kazuyuki, Tamura Ryuichi, Tsukada Naotoshi, CEPR's policy portal 2017. https://voxeu.org/article/new-indicators-science-intensity-industry (accessed December 15, 2017).

The Global Information and Communications Technologies (ICT) Unit. The World Bank "IT Skills Assessment in Armenia" (2014). 